\title{
Clinical characteristics of infant neuroblastoma and a summary of treatment outcome
}

\author{
YI ZHANG $^{1,2}$, DONGSHENG HUANG ${ }^{1}$, WEILING ZHANG ${ }^{1}$, SUOQIN TANG $^{2}$, \\ TAO HAN ${ }^{1}, \mathrm{XIA} \mathrm{ZHU}^{1}$, AIPING LIU ${ }^{1}$ and TIAN ZHI ${ }^{1}$ \\ ${ }^{1}$ Department of Pediatrics, Beijing Tongren Hospital, Capital Medical University, Beijing 100176; \\ ${ }^{2}$ Department of Pediatrics, Chinese People's Liberation Army General Hospital, \\ Medical School of Chinese People's Liberation Army, Beijing 100039, P.R. China
}

Received May 30, 2015; Accepted September 30, 2016

DOI: $10.3892 / 01.2016 .5353$

\begin{abstract}
Neuroblastoma (NB) is the most common malignant solid tumor in the peripheral nervous system in infants and young children, with a high degree of malignancy. The clinical characteristics and prognosis of NB in infants are unique. The present study retrospectively analyzed the prognosis of infant $\mathrm{NB}$ cases that underwent different treatments. In total, 16 infant NB cases (10 male and 6 female) who were treated between February 2007 and August 2013 in Beijing Tongren Hospital (Beijing, China), were enrolled in the study. They were diagnosed by pathology, medical imaging and serology methods. These 16 patients were subjected to comprehensive treatment, including chemotherapy, surgery, autologous peripheral blood stem cell transplantation (APBSCT) and radiation therapy. The age distribution and clinical stages were: 5 cases $(31.25 \%)$ at $\leq 3$ months ( 4 cases at stage $4 \mathrm{~s}$ and 1 case at stage 4 ); 2 cases $(12.5 \%)$ at $3-6$ months (both at stage $4 \mathrm{~s})$; and 9 cases $(56.25 \%)$ at 6-12 months ( 2 cases at stage $4 \mathrm{~s}, 6$ cases at stage 4 and 1 case at stage 3 ). Subsequent to treatment, nicotinic acid esterase (NSE) levels in the patient's serum significantly decreased. The NSE levels in 12 cases $(75 \%)$ dropped to the reference value $(0-15.2 \mathrm{ng} / \mathrm{dl})$. All the NB infants at stages $4 \mathrm{~s}$ and 3 were treated by surgery and chemotherapy (100\%; 9/9). The 5 NB infants at stage 4 were treated by chemotherapy and surgery. For the 2 NB infants who experienced recurrence or whose condition was partially relieved after conventional therapy, APBSCT therapy was applied. At the last follow-up in September 2014, 13 cases $(81.25 \%)$ presented with a complete response, 2 cases $(12.50 \%)$ with a partial response and 1 case $(6.25 \%)$ with recurrence after transplantation (progressive disease). In conclusion, infant NB cases are sensitive to chemotherapy, particularly the cases at stage 4 s, which occur
\end{abstract}

Correspondence to: Dr Dongsheng Huang, Department of Pediatrics, Beijing Tongren Hospital, Capital Medical University, 1 Dongjiaomin Alley, Dongcheng, Beijing 100176, P.R. China

E-mail: hds5180@sina.com

Key words: neuroblastoma, infant, stage 4s, chemotherapy, surgery, clinical response with a higher incidence, but with a better clinical response and prognosis after treatment.

\section{Introduction}

Neuroblastoma (NB) is the most common malignant solid tumor from the peripheral nervous system. The disease originates from neural crest cells and accounts for $7-10 \%$ of malignant tumors among children (1-3). Several genetic abnormalities associated with NB have been characterized, including DNA content, gain of chromosome arm 17q or deletion of chromosome arms 1p and 11q (4-8). NB occurs frequently in infants, with a high degree of malignancy. According to the stage standard of the International Neuroblastoma Staging System (INSS) (9), NB is classified into stages 1-4, with a special stage $4 \mathrm{~s}$. Stage $4 \mathrm{~s}$ cases occur in infants who are $<1$ year old. These cases are sensitive to chemotherapy, with a better prognosis than cases at stages 3 and 4 . NB infants are mainly treated with surgery in conjunction with chemotherapy and radiotherapy. The response to the treatment also depends on the age of the patients and their sensitivity to chemotherapy. Previous studies have shown that the most robust prognostic factors are age, stage, histology and amplification of the N-Myc oncogene (10-14). N-Myc is a member of the Myc family of oncogenic proteins, which are well known for their association with a large proportion of human forms of cancer (15). NB patients with amplification of the N-Myc gene tend to have poor clinical outcomes (16).

The present study retrospectively analyzed the cases of 16 infants with NB who were $<1$ year old and treated in Beijing Tongren Hospital (Beijing, China) between February 2007 and August 2013. The analysis included the clinical characteristics at diagnosis, the treatments used and the response to the therapy.

\section{Patients and methods}

Patient information. A total of 16 infant NB cases diagnosed by imaging serology and/or pathological histology were admitted to Beijing Tongren Hospital between February 2007 and August 2013. Ethical approval was obtained from the Ethics Committee of Beijing Tongren Hospital. Informed consent was gained from the legal guardians of all infant patients. 
Diagnosis and clinical stages. The NB patients were diagnosed based on histopathology results after surgical excision or pathological biopsy, with reference to the onset age, the primary site, any visible tumor calcification on a primary site computed tomography (CT) scan and the neuron-specific tumor marker nicotinic acid esterase (NSE). The criteria for inclusion of the patients were as follows: i) An onset age of $<12$ months. ii) A diagnosis confirmed by biopsy and pathological examination after surgery. If the patient presented with a large tumor (diameter $>10 \mathrm{~cm}$ ) at the initial diagnosis, the diagnosis was based on the localization of the primary site by $\mathrm{CT} / \mathrm{magnetic}$ resonance imaging, with serum NSE above the normal value. iii) Patients with guardians who were collaborative in required treatments, re-diagnosis and follow-up. The exclusion criteria were: i) Patients that did not fit the inclusion criteria; and ii) patients whose guardians decided to stop treatment prior to completion.

Treatments. Patients were mainly treated by chemotherapy combined with surgery. For those infants with a large mass (diameter $>10 \mathrm{~cm}$ ) and an age of $<3$ months, treatment with chemotherapy was applied prior to surgery. For infants $<6$ months old, $\leq 6$ cycles of chemotherapy were performed, while for infants between 6 and 12 months, $\leq 9$ cycles of chemotherapy were performed. For stage 4 patients who showed recurrence or exhibited no initial response to chemotherapy, the treatment was extended to 12-18 cycles, and high-dose chemotherapy combined with autologous peripheral blood stem cells transplantation (APBSCT) was applied.

Selection of chemotherapy. Chemotherapies used in this study are shown in Table I. Patients $<6$ months old were treated with a cisplatin, etoposide, cyclophosphamide and doxorubicin (PECA) regimen or a low-dose topotecan and cyclophosphamide (TC) regimen for 2-4 cycles prior to surgery and for 4-6 cycles after surgery. Stage 4 patients between 6 and 12 months old were treated with PECA or TC prior to surgery, and a cyclophosphamide, cincristine and daunorubicin/etoposide and cisplatin (CDV/CIE) regimen (alternately) following surgery. Patients at stage 3 were treated with PECA or low-dose $\mathrm{CDV} / \mathrm{CIE}$ (alternately).

High-dose chemotherapy combined with APBSCT. According to Children's Oncology Group (COG) guidelines (17), patients received either a carboplatin, etoposide and melphalan (CEM) regimen or busulfan/melphalan as conditioning for APBSCT. Patients with bone metastasis or bone marrow metastasis received ${ }^{131} \mathrm{I}$-metaiodobenzylguanidine $\left({ }^{131} \mathrm{I}-\mathrm{MIBG}\right)$ prior to pretreatment.

Radiation treatment. Patients $\leq 1$ year old 23re not recommended to undergo radiotherapy. Patients could be treated with radiotherapy for metastases when they were $>2$ years old.

Fluorescence in situ hybridization (FISH). Peripheral blood specimens from patients with the presence of spontaneously dividing tumor cells were collected for the FISH test. The $\mathrm{N}$-myc gene probe (Invitrogen; Thermo Fisher Scientific, Waltham, MA, USA), 2,143-bp long, was cloned and marked as a digoxin DNA probe. A DIG DNA Labeling and Detection kit (Boehringer Ingelheim, Mannheim, Germany) was used for the FISH experiments, according to the manufactor's protocols. The N-myc copy number was scored by counting
Table I. Chemotherapy strategies for infant NB cases.

\begin{tabular}{llll}
\hline \multirow{2}{*}{ Strategy } & \multicolumn{1}{c}{ Drugs } & \multicolumn{1}{c}{ Dosage } & \multicolumn{1}{c}{$\begin{array}{l}\text { Treatment } \\
\text { time point }\end{array}$} \\
\hline PECA & P: Cisplatin & $90 \mathrm{mg} / \mathrm{m}^{2}$ & D1 \\
& E: Etoposide & $100 \mathrm{mg} / \mathrm{m}^{2}$ & D3 \\
& C: Cyclophosphamide & $150 \mathrm{mg} / \mathrm{m}^{2}$ & D7-13 \\
& A: Doxorubicin & $30 \mathrm{mg} / \mathrm{m}^{2}$ & D14 \\
TC & T: tTopotecan & $1.2 \mathrm{mg} / \mathrm{m}^{2}$ & D1-5 \\
& C: Cyclophosphamide & $13.3 \mathrm{mg} / \mathrm{kg} / \mathrm{d}$ & D1-5 \\
CDV & C: Cyclophosphamide & $1.5 \mathrm{~g} / \mathrm{m}^{2}$ & D1-2 \\
& \multicolumn{1}{c}{ Mesna } & $420 \mathrm{mg} / \mathrm{m}^{2}$ & $0,3,6$ and \\
& & & $9 \mathrm{~h}, \mathrm{D} 1-2$ \\
& V: Vincristine & $0.53 \mathrm{mg} / \mathrm{m}^{2}$ & D1-3 \\
& D: Daunorubicin & $20 \mathrm{mg} / \mathrm{m}^{2}$ & D1-3 \\
CiE & E: Etoposide & $160 \mathrm{mg} / \mathrm{m}^{2}$ & D1-3 \\
& P: Cisplatin & $40 \mathrm{mg} / \mathrm{m}^{2}$ & D1-4 \\
\hline
\end{tabular}

D, day.

and averaging the number of fluorescence signals per interphase nucleus. Cases with a $\mathrm{N}$-myc copy number of $>4$ were considered positive for $\mathrm{N}$-myc amplification.

Serum NSE test. Serum NSE level was assessed with the Roche Elecsys 2010 system (Roche Diagnostics, Basel, Switzerland). The NSE electrochemical luminescence detection kit was also purchased from Roche. Patient serum samples were processed according to the manufactor's protocols. The reference serum NSE value was $0-15.2 \mathrm{ng} / \mathrm{dl}$.

Clinical responses and follow-up. The clinical responses were categorized as follows (18): i) Complete response (CR): Tumors totally disappeared after treatment and could not be detected by CT. The level of $\alpha$-fetoprotein in the serum stayed normal for $>4$ weeks. ii) Partial response (PR): Tumors were shrunk by $>50 \%$ and there were no new lesions. CR and PR cases were counted as cases with effective treatment. iii) Stable disease (SD): Tumors were shrunk by $<50 \%$. The primary tumor size was not increased and there were no new lesions. iv) No response (NR): Tumors were shrunk by $<25 \%$ and there were no new lesions. v) Progressive disease (PD): Tumor size increased by $>25 \%$ or new lesions appeared. Toxicity was evaluated according to World Health Organisation classification (19), and classified into stages I-IV.

Follow-up started when the regular chemotherapy cycles were complete and ended by recurrence, mortality or the decision to end therapy. The last follow-up was performed on February 2014.

Statistical analysis. Enumeration data were analyzed by $\chi^{2}$ test and measurement data were analyzed by Student's t-test. $\mathrm{P}<0.05$ was considered to indicate a statistically significant difference. The survive rate was analyze by Kaplan-Meier method. All statistical analyses were performed using SPSS software (version 17.0; SPSS Inc., Chicago, IL, USA). 
Table II. Clinical features, treatments and responses of 16 infant neuroblastoma cases.

\begin{tabular}{|c|c|c|c|c|c|c|c|}
\hline Case no. & Gender & Age, months & Stage & Primary site & Metastatic site & Treatments & Response \\
\hline 1 & Male & 3 & 4 & $\begin{array}{l}\text { Right upper } \\
\text { mediastinum }\end{array}$ & $\begin{array}{l}\text { Superior lobe of right } \\
\text { lung, pleura, thoracic } \\
\text { vertebrae, spinal canal }\end{array}$ & $\begin{array}{l}\text { Surgery }+ \text { chemotherapy } \\
\text { after surgery }\end{array}$ & $\mathrm{CR}$ \\
\hline 2 & Male & 9 & 4 & Breast neoplasm & $\begin{array}{l}\text { Pleural metastasis, } \\
\text { lymph node, thoracic } \\
\text { vertebrae, spinal canal }\end{array}$ & $\begin{array}{l}\text { Surgery }+ \text { chemotherapy } \\
\text { prior to/after surgery }\end{array}$ & CR \\
\hline 3 & Male & 10 & 4 & $\begin{array}{l}\text { Posterior } \\
\text { mediastinum }\end{array}$ & $\begin{array}{l}\text { Right lung, thoracic } \\
\text { cavity }\end{array}$ & $\begin{array}{l}\text { Surgery }+ \text { chemotherapy } \\
\text { after surgery }\end{array}$ & $\mathrm{CR}$ \\
\hline 4 & Male & 3 & $4 \mathrm{~s}$ & $\begin{array}{l}\text { Right adrenal } \\
\text { gland }\end{array}$ & $\begin{array}{l}\text { Intrahepatic metastasis } \\
\text { (diffuse), hemangioma, } \\
\text { spleen }\end{array}$ & $\begin{array}{l}\text { Surgery }+ \text { chemotherapy } \\
\text { prior to/after surgery }\end{array}$ & $\mathrm{CR}$ \\
\hline 5 & Male & 3 & $4 \mathrm{~s}$ & $\begin{array}{l}\text { Mainly right } \\
\text { adrenal gland }\end{array}$ & $\begin{array}{l}\text { Intrahepatic metastasis } \\
\text { (diffuse) }\end{array}$ & $\begin{array}{l}\text { Surgery }+ \text { chemotherapy } \\
\text { prior to/after surgery }\end{array}$ & $\mathrm{CR}$ \\
\hline 6 & Male & 2 & $4 \mathrm{~s}$ & Left adrenal gland & $\begin{array}{l}\text { Intrahepatic metastasis } \\
\text { (diffuse) }\end{array}$ & $\begin{array}{l}\text { Surgery + chemotherapy } \\
\text { after surgery }\end{array}$ & $\mathrm{CR}$ \\
\hline 7 & Female & 1 & $4 \mathrm{~s}$ & $\begin{array}{l}\text { Right adrenal } \\
\text { gland }\end{array}$ & $\begin{array}{l}\text { Intrahepatic metastasis } \\
\text { (diffuse) }\end{array}$ & $\begin{array}{l}\text { Surgery }+ \text { chemotherapy } \\
\text { prior to/after surgery }\end{array}$ & $\mathrm{CR}$ \\
\hline 8 & Male & 11 & 4 & $\begin{array}{l}\text { Left retroperitoneal } \\
\text { space }\end{array}$ & $\begin{array}{l}\text { Liver, lymph node, } \\
\text { skull and left iliac } \\
\text { fossa }\end{array}$ & $\begin{array}{l}\text { Surgery + chemotherapy } \\
\text { prior to/after } \\
\text { surgery + APBSCT }\end{array}$ & $\mathrm{CR}$ \\
\hline 9 & Female & 11 & $4 \mathrm{~s}$ & $\begin{array}{l}\text { Left adrenal } \\
\text { gland }\end{array}$ & $\begin{array}{l}\text { Left abdominal } \\
\text { subcutaneous, } \\
\text { lymph node }\end{array}$ & $\begin{array}{l}\text { Surgery + chemotherapy } \\
\text { after surgery }\end{array}$ & CR \\
\hline 10 & Male & 12 & 3 & $\begin{array}{l}\text { Right retroperitoneal } \\
\text { space }\end{array}$ & None & $\begin{array}{l}\text { Surgery }+ \text { chemotherapy } \\
\text { after surgery }\end{array}$ & $\mathrm{CR}$ \\
\hline 11 & Male & 12 & 4 & $\begin{array}{l}\text { Left retroperitoneal } \\
\text { space }\end{array}$ & $\begin{array}{l}\text { Lumbar vertebrae, } \\
\text { spinal neoplasm } \\
\text { canal invasion }\end{array}$ & $\begin{array}{l}\text { Surgery + chemotherapy } \\
\text { after surgery }\end{array}$ & PR \\
\hline $12^{\mathrm{a}}$ & Male & 5 & $4 \mathrm{~s}$ & $\begin{array}{l}\text { Left adrenal } \\
\text { gland, right } \\
\text { retroperitoneal space }\end{array}$ & $\begin{array}{l}\text { Liver, skin, bone, } \\
\text { retroperitoneal } \\
\text { space }\end{array}$ & $\begin{array}{l}\text { Surgery + chemotherapy } \\
\text { after surgery }\end{array}$ & $\mathrm{CR}$ \\
\hline 13 & Female & 11 & 4 & Neck, mediastinum & $\begin{array}{l}\text { Neck lymph node, } \\
\text { thoracic vertebrae }\end{array}$ & $\begin{array}{l}\text { Surgery }+ \text { chemotherapy } \\
\text { prior to/after surgery }\end{array}$ & $\mathrm{CR}$ \\
\hline 14 & Female & 11 & 3 & Front pelvic sacrum & Spinal canal invasion & $\begin{array}{l}\text { Surgery }+ \text { chemotherapy } \\
\text { prior to/after surgery }\end{array}$ & PR \\
\hline 15 & Female & 11 & 4 & $\begin{array}{l}\text { Upper and right } \\
\text { retroperitoneal space }\end{array}$ & $\begin{array}{l}\text { Left subclavian } \\
\text { lymph node, } \\
\text { retroperitoneal } \\
\text { space, spinal cord }\end{array}$ & $\begin{array}{l}\text { Surgery }+ \text { chemotherapy } \\
\text { prior to/after } \\
\text { surgery }+{ }^{131} \text { I-MIBG } \\
\text { APBSCT }+ \text { radiotherapy }\end{array}$ & PD \\
\hline 16 & Female & 4 & $4 s$ & $\begin{array}{l}\text { Right adrenal } \\
\text { neoplasm }\end{array}$ & $\begin{array}{l}\text { Intrahepatic metastasis } \\
\text { (diffuse) }\end{array}$ & $\begin{array}{l}\text { Surgery }+ \text { chemotherapy } \\
\text { prior to/after surgery }\end{array}$ & CR \\
\hline
\end{tabular}

${ }^{a}$ For case 12, liver metastasis was resected after 2 cycles of chemotherapy upon surgery, followed by chemotherapy for 5 cycles. APBSCT, autologous peripheral blood stem cell transplantation; ${ }^{131} \mathrm{I}-\mathrm{MIBG},{ }^{131} \mathrm{I}$-metaiodobenzylguanidine; $\mathrm{CR}$, complete response; PR, partial response; $\mathrm{PD}$, progressive disease.

\section{Results}

Patient characteristics. Among the 16 cases, 10 patients were male and 6 were female, with a median age of 9.5 months (range, 1-12 months old). Overall, 5 cases (31.25\%) were $<3$ months old ( 4 cases at stage $4 \mathrm{~s}$ and 1 case at stage 4 ), 2 cases $(12.5 \%)$ were 3-6 months old (both at stage $4 \mathrm{~s}$ ) and
9 cases $(56.25 \%)$ were $6-12$ months old (1 case at stage $4 \mathrm{~s}$, 6 cases at stage 4 and 2 cases at stage 3 ). The data indicated that the frequency of stage 4 s cases in patients $<6$ months old was significantly higher than the frequency of stage $4 \mathrm{~s}$ cases between 6 and 12 months old $\left(\chi^{2}\right.$ test, $\left.P=0.012\right)$. Primary sites were as follows: Mediastinum in 5 cases, pelvic cavity in 1 case, and retroperitoneal and adrenal area in 10 cases. There 

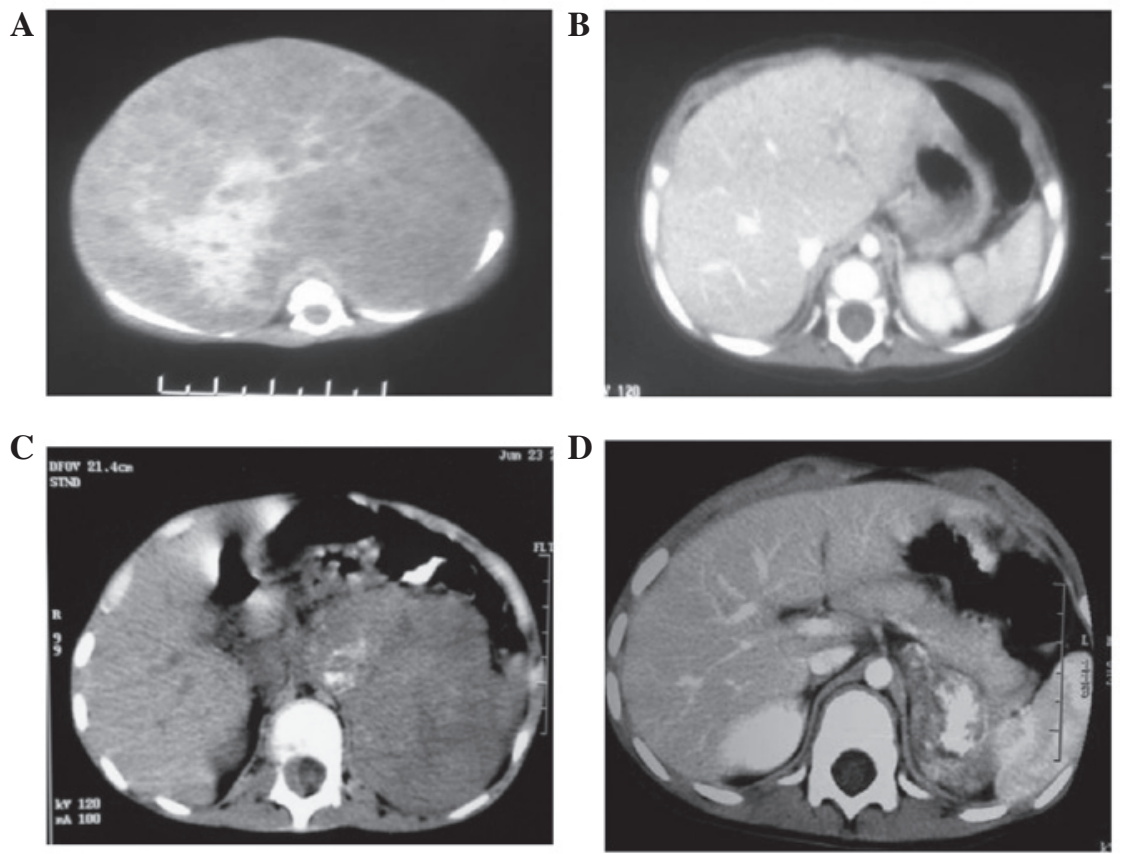

Figure 1. CT images of patients. (A and B) CT images of case number 7 (A) prior to and (B) after treatment (surgery and 8 cycles of chemotherapy). The patient presented with tumor metastases in the adrenal gland and intrahepatic areas. Following treatment, the case exhibited a complete response. (C and D) CT images of case number 8 (C) prior to and (D) after treatment (surgery, chemotherapy and autologous peripheral blood stem cell transplantation). CT, computed tomography.

were 6 cases with tumors exhibiting N-myc gene amplification ( $>4$ copies), and only case number 15 had a tumor with $>10$ copies. All the clinical information is shown in Table II.

The serum NSE levels in all 16 cases $(100 \%)$ were above the normal value at the initial diagnosis, with a median of $59.95 \mathrm{ng} /$ dl (range, 17.48-264 ng/dl). After treatment, the serum NSE levels of all cases were significantly decreased. The serum NSE levels were within the reference range $(0-15.2 \mathrm{ng} / \mathrm{dl})$ in 12 cases $(75.0 \%)$, and were slightly above the reference range in the remaining 3 cases $(18.75 \%)$.

Summary of treatments, clinical responses and survival. In this study, 2 cases were diagnosed by biopsy pathology, 7 cases were diagnosed by surgery and the remaining 7 cases were diagnosed by CT. The International Neuroblastoma Staging System (INSS) is a post-surgical staging system, which was developed to establish a consensus approach for pre-treatment risk stratification of patients with neuroblastoma (20). According to INSS, 2 cases were stage 3 disease (favorable histopathological features), 7 cases were stage 4 (unfavorable histopathological features) and 7 cases were stage 4S ( $<1$ year old with unfavorable biological features). According to the INSS, 2 cases were at stage 3, 7 cases were at stage 4 and the remaining 7 cases were at stage $4 \mathrm{~s}$. According to COG and Neuroblastoma Risk Grouping (21), 7 cases were in the high-risk group, 7 cases were in the intermediate-risk group and 2 cases were in the low-risk group.

From the initial diagnosis to the last follow-up, 7 cases (case numbers 2, 4, 5, 7, 13, 14 and 16) received surgery plus chemotherapy prior to/after the surgery. Another 7 cases (case numbers 1, 3, 6, 9, 10, 11 and 12) received surgery plus chemotherapy after the surgery. A single case (case number 8) received surgery plus chemotherapy prior to/after surgery, as well as APBSCT. Another case (case number 15) received surgery plus chemotherapy prior to/after surgery, as well as APBSCT with ${ }^{131}$ I-MIBG.

Until the last follow-up in September 2014, the median follow-up time of the patients was 29.5 months. As shown in Table II, 13 cases $(81.25 \%)$ presented with a CR, 2 cases with a PR $(12.5 \%)$ and 1 case with PD $(6.25 \%)$. The patient with $\mathrm{PD}$ (case number 15) experienced recurrence following transplantation and now survived with tumors. The prognosis of the stage 4 cases was significantly worse than that of the stage $4 \mathrm{~s}$ and stage 3 cases ( $\chi^{2}$ test, $P=0.045$ ). There was no significant difference in the prognosis between the stage $4 \mathrm{~s}$ and stage 3 cases $(\mathrm{P}>0.05)$.

At the time of the last follow-up, all patients remained alive. Kaplan-Meier analysis showed that the overall survival rate for 2 years was $100 \%$ (16/16). The event-free survival rate was $81.25 \%(13 / 16)$.

Outcome of PECA strategy for stage 4 s patients. A total of 7 cases at stage $4 \mathrm{~s}$ were treated with PECA prior to and after surgery; of these, 5 cases $(71.4 \%)$ received 6 cycles of chemotherapy, 1 case $(14.3 \%)$ received 7 cycles of chemotherapy and another 1 case $(14.3 \%)$ received 8 cycles of chemotherapy. Until the last follow-up, 6 cases presented with a CR and 1 case with a PR (case number 12). The CT images from a CR case (case number 7 ) prior to and after the surgery and PECA treatment are shown in Fig. 1A and B. Case number 12 underwent surgery consisting of liver metastasis resection and eventually achieved a CR. The efficiency of the PECA strategy was $100 \%$. Furthermore, the toxicity evaluation for those patients was stage I (slight loss of appetite, vomiting and bone marrow suppression), but all patients recovered after appropriate treatment. 

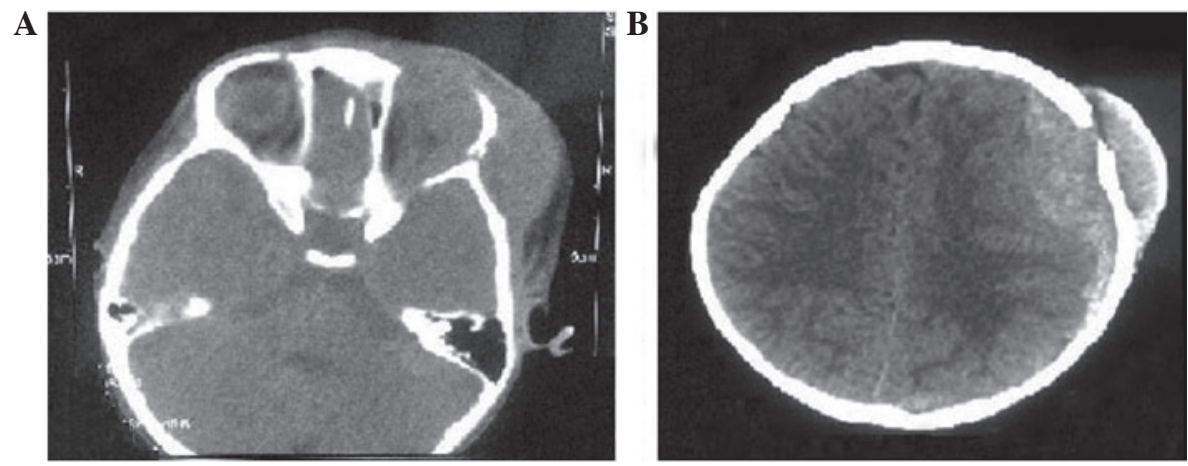

Figure 2. CT images of case number 15 after treatment (surgery, chemotherapy, ${ }^{131}$ I-metaiodobenzylguanidine, autologous peripheral blood stem cell transplantation and radiotherapy). Two cranial CT images at different axial positions. The patient experienced progressive disease, as shown by tumor recurrence in the skull, with bleeding in dura mater. CT, computed tomography.

High-dose chemotherapy combined with APBSCT. In this study, 2 patients at stage 4 were treated with high-dose chemotherapy combined with APBSCT after regular surgery and chemotherapy (case numbers 8 and 15). Case number 8 was an 11-month-old who had presented with a tumor in the left retroperitoneal space, with metastasis to the lymph nodes at the left iliac fossa, liver and skull. This patient received 2 cycles of chemotherapy prior to surgery and 8 cycles of chemotherapy after surgery, which did not lead to a CR. Hence, this case was further treated with CEM combined with APBSCT. Pirarubicin resulted in cardiomegaly and stage III chronic cardiac insufficiency after regular chemotherapy. APBSCT treatment and oral administration of small-dose digoxin $(0.125 \mathrm{mg} /$ day $)$ for 6 months aided the recovery of echocardiography results and cardiac function. By the time of the last follow-up, the patient had survived for 75 months (Fig. 1C and D).

Case number 15 initially exhibited a fever and diarrhea. Biopsy and FISH detection showed that this patient had strong N-myc amplification ( $>10$ copies). The patient was treated with 3 cycles of regular chemotherapy, then surgery followed by 6 cycles of chemotherapy, and a second surgery. Treatment was continued with ${ }^{131}$ I-MIBG combined with APBSCT in another hospital. At 2 months post-transplantation, extensive metastasis to the skull occurred, which was followed by 11 cycles of chemotherapy with a total dose of $20 \mathrm{~Gy}$. Until the date of follow-up, this patient had survived with PD, and the time course of the disease was 47 months (Fig. 2).

Toxicity evaluation. The toxicity evaluation for these 16 patients was as follows: 14 cases were at stage I, 1 case was at stage II (case number 7) and 1 case was at stage III (case number 8). Cases with toxicity at stage I showed bone marrow inhibition and the leukocyte count in the peripheral blood reached the lowest value of $0.85 \pm 0.23 \times 10^{9} / 1$ (normal range, $\left.6.0-17.5 \times 10^{9} / 1\right)$. The average recovery time was $6.2 \pm 1.3$ days. Case number 7 with toxicity at stage II showed bone marrow inhibition and an increase in platelet count in the peripheral blood (1,100x $10^{9} / 1$; normal range, $\left.220-460 \times 10^{9} / 1\right)$. Case number 8 with toxicity at stage III showed bone marrow inhibition and dilated cardiomyopathy. Following regular treatment with small-dose digoxin for 6 months, the dilated cardiomyopathy was relieved.

\section{Discussion}

NB in children usually initiates in the retroperitoneal space, adrenal area, mediastinum, spine or pelvic cavity (22). NB in infants, particularly those $<6$ months old, is usually found at stage $4 \mathrm{~s}$ (22). Characteristics of this disease include a young onset of disease, incomplete development of visceral organ function, a low body weight and huge tumors (22). Certain tumors are found during the prenatal diagnosis prior to delivery (22). In the present study, patients $<6$ months old were all at stage $4 \mathrm{~s}$, which was consistent with the results of previous studies $(23,24)$. According to the COG classification, the majority of cases were in the low- and intermediate-risk groups ( 9 cases), and the rest were in the high-risk group (7 cases). According to the results, although NB malignancy is high and the progression is fast, the risk of NB cases occurring within patients $<1$ year old is relatively mild.

NSE is a glycolytic enzyme involved in the glycolysis pathway. NSE is usually expressed in neurons, peripheral nerve tissues and neuroendocrine tissues (such as brain spinal cord and branching peripheral nerves), and in the cell system (such as endocrine cells, which can take in amine and amine precursor and produce peptide and/or amine hormones) (25-28). NSE is released prior to cell damage and serve as specific markers for mature neuroendocrine neoplasms (29). Recently, NB immunohistochemistry revealed that NB patients are all NSE-positive (with better staining intensity in intermediate-risk NB) (30). In the present study, the serum NSE levels in the 16 cases were all above the normal range at the time of diagnosis. Following treatment, the NSE levels were decreased to normal in $75 \%$ of cases, indicating that although the malignance of infant NB was slightly less than that in elder children, and certain patients at stage $4 \mathrm{~s}$ experience tumor regression without any treatment, the serum NSE level remains one of the important indicators for diagnosis and treatment response.

It has been reported that the different primary sites of NB exhibit important differences in terms of clinical and biological features (31). In the present study, a direct correlation was not observed between primary tumor sites and prognosis, most likely due to the limited number of cases. However, the primary tumor site affects numerous aspects of NB treatment and progression, including the decision for primary surgery, residual diseases, and tumor metastasis 
and invasion. Therefore, the primary tumor site still impacts the clinical outcome. For instance, an initial resection of the tumor in case number 14 was not performed, as this case had a primary tumor site at the front pelvic sacrum, and during chemotherapy prior to surgery, spinal canal invasion was observed in this case.

According to the COG and Pediatrics Oncology Group guidelines for NB treatment, and the characteristics of NB during diagnosis (the size and location of the primary tumor, metastasis and the tolerance degree to surgery), the NB treatments include capacity reduction chemotherapy prior to surgery, chemotherapy after surgery, and high-dose chemotherapy combined with ABPSCT $(31,32)$. However, $30 \%$ of NB infants at stage $4 \mathrm{~s}$, particularly those $<6$ months old, experience tumor regression. Hence, the choice of whether to treat with chemotherapy, the decision on the number of cycles of chemotherapy and the choice of whether to treat with APBSCT have not been standardized in China, as well as in other countries. Akramipour et al (33) reported that 1 patient at stage 1 survived event-free after surgery only and 36 months of follow-up. In 2012, Nuchtern et al (34) reported that $87 \mathrm{NB}$ cases $<6$ months old had a $>90 \% 3$-year survival rate after surgery only and observation. However, it is believed that mild- and high-risk cases should be treated with chemotherapy. Capasso et al (35) showed that during 2007-2012, the condition of 5 cases at stage $4 \mathrm{~s}$ treated with a cyclophosphamide, vincristine and Adriamycin, and carboplatin and etoposide strategies was completely relieved, while 1 case had not accepted chemotherapy for 15 months, and was then treated with 2 cycles of chemotherapy during disease progression until the condition was eventually relieved. In the present study, all 16 cases were treated with chemotherapy. Case number 8 was partially relieved after surgery combined with 10 cycles of chemotherapy, and case number 15 at stage 4 with amplification of $\mathrm{N}$-myc was treated with high-dose chemotherapy combined with APBSCT. The former survived without disease and the latter experienced progression of the recurrence after APBSCT. Hence, based on the international and domestic studies, and the efficacy and the safety evaluation of these 16 cases, with regard to chemotherapy for NB infants, the cases in the mild- and high-risk groups were treated with chemotherapy. Depending on the size of primary tumors and whether surgery can achieve complete excision, cases in the low-risk group can be treated with chemotherapy. NB infants, who are less than 6 months old and have no N-myc gene amplification, may undergo surgery followed by low-dose chemotherapy to reduce the time of tumor relief and improve survival quality. Chemotherapy could be carefully chosen according to the original diagnosis to achieve tolerance and efficiently inhibit tumor growth. However, for APBSCT application, although 2 cases in the present study were treated with APBSCT, 1 patient experienced recurrence after 2 months of treatment. Therefore, we believe that after considering the advantages and disadvantages, NB infants, particularly those at stage $4 \mathrm{~s}$, are not suitable for APBSCT treatment. Although the responses for cases at stage 4 were not totally satisfactory, only 1 case exhibited recurrence, 2 cases were partially relieved and survived with tumors, and the remaining 4 cases had a CR and event-free survival, indicating that NB infants have a high response rate and a high survival rate. Hence, the treatment confidence of family members of patients should be buoyed to further improve the cure rate of NB patients.

In conclusion, the main treatments for NB infants were surgery and chemotherapy. Although NB infants have a low onset age, a serious initial condition, a higher risk of chemotherapy and more difficulties during surgery than older children, appropriate, reasonable and comprehensive treatment can achieve high relief and survival rates.

\section{Acknowledgements}

This study was supported by the \#215 High-Level Talent Program of Beijing Municipal Health Bureau (grant no. 20153-018, to Y.Z.).

\section{References}

1. Evans A: Neuroblastoma: A historical perspective 1864-1998. In: Neuroblastoma. Brodeur GM, Sawada T, Tsuchida Y and Voûte PA (eds). Elsevier Science, Amsterdam, pp1-7, 2000.

2. Yáñez Y, Grau E, Rodríguez-Cortez VC, Hervás D, Vidal E, Noguera R, Hernández M, Segura V, Cañete A, Conesa A, et al: Two independent epigenetic biomarkers predict survival in neuroblastoma. Clin Epigenetics 7: 16, 2015.

3. London WB, Castleberry RP, Matthay KK, Look AT, Seeger RC, Shimada H, Thorner P, Brodeur G, Maris JM, Reynolds CP and Cohn SL: Evidence for an age cutoff greater than 365 days for neuroblastoma risk group stratification in the children's oncology group. J Clin Oncol 23: 6459-6465, 2005.

4. Look AT, Hayes FA, Shuster JJ, Douglass EC, Castleberry RP, Bowman LC, Smith EI and Brodeur GM: Clinical relevance of tumor cell ploidy and N-myc gene amplification in childhood neuroblastoma: A pediatric oncology group study. J Clin Oncol 9: 581-591, 1991.

5. Caron H: Allelic loss of chromosome 1 and additional chromosome 17 material are both unfavourable prognostic markers in neuroblastoma. Med Pediatr Oncol 24: 215-221, 1995.

6. Lampert F, Rudolph B, Christiansen H and Franke F: Identical chromosome 1p breakpoint abnormality in both the tumor and the constitutional karyotype of a patient with neuroblastoma. Cancer Genet Cytogenet 34: 235-239, 1988.

7. Cohn SL, Pearson AD, London WB, Monclair T, Ambros PF Brodeur GM, Faldum A, Hero B, Iehara T, Machin D, et al: The international neuroblastoma risk group (INRG) classification system: An INRG task force report. J Clin Oncol 27: 289-297, 2009.

8. Spitz R, Hero B, Simon T and Berthold F: Loss in chromosome $11 q$ identifies tumors with increased risk for metastatic relapses in localized and 4S neuroblastoma. Clin Cancer Res 12: 3368-3373, 2006.

9. Castleberry RP: Consistently investigating the inconsistent nature of neuroblastoma. J Pediatr Hematol Oncol 21: 178-180, 1999.

10. Irwin MS and Park JR: Neuroblastoma: Paradigm for precision medicine. Pediatr Clin North Am 62: 225-256, 2015.

11. Monclair T, Brodeur GM, Ambros PF, Brisse HJ, Cecchetto G, Holmes K, Kaneko M, London WB, Matthay KK, Nuchtern JG, et al: The international neuroblastoma risk group (INRG) staging system: An INRG task force report. J Clin Oncol 27: 298-303, 2009.

12. Brodeur GM, Seeger RC, Schwab M, Varmus HE and Bishop JM: Amplification of $\mathrm{N}$-myc in untreated human neuroblastomas correlates with advanced disease stage. Science 224: 1121-1124, 1984.

13. Seeger RC, Brodeur GM, Sather H, Dalton A, Siegel SE, Wong KY and Hammond D: Association of multiple copies of the N-myc oncogene with rapid progression of neuroblastomas. N Engl J Med 313: 1111-1116, 1985.

14. Shimada H, Ambros IM, Dehner LP, Hata J, Joshi VV, Roald B, Stram DO, Gerbing RB, Lukens JN, Matthay KK, et al: The international neuroblastoma pathology classification (the Shimada system). Cancer 86: 364-372, 1999.

15. Dang CV: MYC on the path to cancer. Cell 149: 22-35, 2012. 
16. Cheng JM, Hiemstra JL, Schneider SS, Naumova A, Cheung NK Cohn SL, Diller L, Sapienza C and Brodeur GM: Preferential amplification of the paternal allele of the N-myc gene in human neuroblastomas. Nat Genet 4: 191-194, 1993.

17. Landier W1, Bhatia S, Eshelman DA, Forte KJ, Sweeney T, Hester AL, Darling J, Armstrong FD, Blatt J, Constine LS, et al: Development of risk-based guidelines for pediatric cancer survivors: the Children's Oncology Group Long-Term Follow-Up Guidelines from the Children's Oncology Group Late Effects Committee and Nursing Discipline. J Clin Oncol 22: 4979-4990, 2004.

18. Malogolowkin MH, Katzenstein HM, Krailo M, Chen Z Quinn JJ, Reynolds $M$ and Ortega JA: Redefining the role of doxorubicin for the treatment of children with hepatoblastoma. J Clin Oncol 26: 2379-2383, 2008.

19. Franklin HR,Simonetti GP,Dubbelman AC, ten BokkelHuininkWW, Taal BG, Wigbout G, Mandjes IA, Dalesio OB and Aaronson NK Toxicity grading systems. A comparison between the WHO scoring system and the Common Toxicity Criteria when used for nausea and vomiting. Ann Oncol 5: 113-117, 1994

20. Brodeur GM, Seeger RC, Barrett A, Berthold F, Castleberry RP, D'Angio G, De Bernardi B, Evans AE, Favrot M, Freeman AI, et al: International criteria for diagnosis, staging, and response to treatment in patients with neuroblastoma. J Clin Oncol 6: 1874-1881.

21. Cohn SL, Pearson AD, London WB, Monclair T, Ambros PF, Brodeur GM, Faldum A, Hero B, Iehara T, Machin D, et al: The International Neuroblastoma Risk Group (INRG) classification system: an INRG Task Force report. J Clin Oncol 27: 289-297, 2009.

22. Dumba M, Jawad N and McHugh K: Neuroblastoma and nephroblastoma: A radiological review. Cancer Imaging 15: 5, 2015.

23. Schleiermacher G, Rubie H, Hartmann O, Bergeron C, Chastagner P, Mechinaud F and Michon J; Neuroblastoma Study Group of the French Society of Paediatric Oncology: Treatment of stage 4s neuroblastoma--report of 10 years' experience of the French Society of Paediatric Oncology (SFOP). Br J Cancer 89: 470-476, 2003

24. Hiyama E, Iehara T, Sugimoto T, Fukuzawa M,Hayashi Y, Sasaki F, Sugiyama M, Kondo S, Yoneda A, Yamaoka H, et al: Effectiveness of screening for neuroblastoma at 6 months of age: a retrospective population-based cohort study. Lancet 371: 1173-1180, 2008.

25. Kushner BH, Modak S, Kramer K, LaQuaglia MP, Yataghene K, Basu EM, Roberts SS and Cheung NK: Striking dichotomy in outcome of MYCN-amplified neuroblastoma in the contemporary era. Cancer 120: 2050-2059, 2014.

26. Ando S, Suzuki M, Yamamoto N, Iida T and Kimura H: The prognostic value of both neuron-specific enolase (NSE) and Cyfra21-1 in small cell lung cancer. Anticancer Res 24: 1941-1946, 2004.
27. Karnak D, Beder S, Kayacan O, Ibis E and Oflaz G. Neuron-specific enolase and lung cancer. Am J Clin Oncol 28: 586-590, 2005

28. Tapia FJ, Polak JM, Barbosa AJ, Bloom SR, Marangos PJ, Dermody $C$ and Pearse AG: Neuron-specific enolase is produced by neuroendocrine tumours. Lancet 1: 808-811, 1981.

29. Gallagher KK, Spector ME,Pepper JP, McKean EL, Marentette LJ and McHugh JB: Esthesioneuroblastoma: Updating histologic grading as it relates to prognosis. Ann Otol Rhinol Laryngol 123: 353-358, 2014.

30. Vo KT, Matthay KK, Neuhaus J,London WB, Hero B, Ambros PF, Nakagawara A, Miniati D, Wheeler K, Pearson AD, et al: Clinical, biologic, and prognostic differences on the basis of primary tumor site in neuroblastoma: A report from the international neuroblastoma risk group project. J Clin Oncol 32: 3169-3176, 2014

31. Stram DO, Matthay KK, O'Leary M, Reynolds CP, Haase GM, Atkinson JB, Brodeur GM and Seeger RC: Consolidation chemoradiotherapy and autologous bone marrow transplantation versus continued chemotherapy for metastatic neuroblastoma: A report of two concurrent children's cancer group studies. J Clin Oncol 14: 2417-2426, 1996

32. Vogelzang NJ, Benowitz SI, Adams S, Aghajanian C, Chang SM, Dreyer ZE, Janne PA, Ko AH, Masters GA, Odenike O, et al: Clinical cancer advances 2011: Annual report on progress against cancer from the American society of clinical oncology. J Clin Oncol 30: 88-109, 2012.

33. Akramipour R, Zargooshi J and Rahimi Z: Infant with concomitant presence of hernia/hydrocele and primary paratesticular neuroblastoma: A diagnostic and therapeutic challenge. J Pediatr Hematol Oncol 31: 349, 2009.

34. Nuchtern JG, London WB, Barnewolt CE, Naranjo A, McGrady PW, Geiger JD, Diller L, Schmidt ML, Maris JM, Cohn SL and Shamberger RC: A prospective study of expectant observation as primary therapy for neuroblastoma in young infants: A children's oncology group study. Ann Surg 256: 573-580, 2012.

35. Capasso M, Cinalli G, Nastro A, Giuliano M, Errico ME, Caccioppoli U, Turco R, Ruotolo S, Vetrella S, De Bernardi B, et al: Symptomatic epidural compression in infants with neuroblastoma: A single-center experience with 5 cases. J Pediatr Hematol Oncol 35: 260-266, 2013. 